\title{
Beneficiation of coal using supercritical water and carbon dioxide extraction: sulfur removal
}

\author{
Matthew J. DeCuir ${ }^{1} \cdot$ Ram B. Gupta ${ }^{1}$ (D) Bhima Sastri ${ }^{2}$
}

Received: 14 February 2020/Revised: 24 March 2020/Accepted: 10 April 2020/Published online: 30 April 2020

(C) The Author(s) 2020, corrected publication 2020

\begin{abstract}
This work explores the use of carbon dioxide, water, and their mixtures as solvent for the precombustion beneficiation of raw coal without using any toxic mineral acids in the temperature range of $200-400{ }^{\circ} \mathrm{C}$. The fluid polarity, ionic constant, and supercritical point can be adjusted by $\mathrm{H}_{2} \mathrm{O} / \mathrm{CO}_{2}$ ratio and temperature. Adding carbon dioxide to hydrothermal fluid also increases the ionization by forming carbonic acid. Extractions with supercritical fluids have several benefits including enhanced mass transport, ease of separation and recycle, wide range of extractive capability and tunability, better inherent safety, and in the case of carbon dioxide and water-low cost. A semi-continuous extraction system was designed and built in which pressure, temperature and the relative flow rates of $\mathrm{CO}_{2}$ and $\mathrm{H}_{2} \mathrm{O}$ can be controlled. Coal powder is kept in a packed bed and the extraction is carried out at 143 bar pressure. Using sulfur as a model heteroatom, extractive efficiency is examined as a function of the temperature, fluid composition, fluid flow, and extraction time. The results indicate that carbon dioxide, water, and supercritical water-carbon dioxide (ScWC) all can effectively extract about 50\% of total sulfur from bituminous coal in $1 \mathrm{~h}$. Extraction above $350{ }^{\circ} \mathrm{C}$ decreased effectiveness, and extraction above the supercritical point of pure water caused hydrothermal carbonization. ScWC extraction may provide necessary control to prevent organic dissolution while removing sulfur.
\end{abstract}

Keywords Coal $\cdot$ Supercritical $\cdot$ Sulfur $\cdot$ Beneficiation $\cdot$ Cleaning $\cdot$ Extraction

\section{Introduction}

Despite recent emergence of natural gas, nuclear, solar, and wind power, coal remains an important energy source to the United States and the world. For example, in 2018, $27.4 \%$ of the United States energy demand was met by burning coal, while for the world the number was even

Ram B. Gupta

rbgupta@vcu.edu

1 Department of Chemical and Life Science Engineering, Virginia Commonwealth University, Richmond, VA 23284-3068, USA

2 Office of Fossil Energy, U.S. Department of Energy, 19901 Germantown Road, Germantown, MD 20874-1290, USA higher, about $40 \%$. According to proven reserves, the world has about 150 years' worth of energy from coal combustion, but only 50 years' worth of energy from oil or natural gas. Furthermore, the United States owns $28 \%$ of the world's coal reserves compared to only $2.3 \%$ of the world's oil reserves. Despite this reserve of coal, the production of coal has been decreasing since 2013 due to the rise of natural gas combined cycle generators, fracking, and concerns over atmospheric and local air pollution. (EIA International Energy Outlook 2017, 2018).

Raw coal contains a high percentage (about $80 \mathrm{wt} \%$ ) of carbon which is combusted to produce $\mathrm{CO}_{2}$ and heat in the power plant; but it also contains harmful components such as sulfur, chlorine, mercury, and heavy metals. When combusted, the harmful components accumulate as bottom ash in the boiler or are swept away in flue gas as fly-ash 
particles and/or noxious gases. Bottom ash can present problems for combustion due to slagging and also pose safe disposal problems. Stringent air quality standards set by the EPA and MATS compliance have placed restrictions on the particulates, sulfur, and $\mathrm{NO}_{x}$ emissions of coal fired power plants due to the realization that serious local and global health concerns can arise from their unabated release. Particulate matter is separated from flue gas using electrostatic filters. Limiting $\mathrm{NO}_{x}$ production is achieved by looping of reaction gases and effective flame control. The three types of sulfur present in coal-organic, pyritic, and sulfides are oxidized to form sulfur dioxide which is toxic to humans if released to the atmosphere and corrosive to plant equipment. Emission of other highly active molecules, such as chlorine and mercury, also contributes to deterioration of the atmospheric environment. Wet flue gas desulphurization (WFGD) units have become the industry standard to limit the sulfur dioxide emissions, with state of the art installations capturing $90 \%-95 \%$ of sulfur and a variable amount of chlorine and mercury. In WFGD, flue gas is passed through concentrated aqueous lime solutions that adsorb $\mathrm{SO}_{x}$ vapors. The resultant slurry can be used to form calcium sulfate dehydrate (i.e., gypsum) but will mostly accumulate as solid waste as elemental sulfur or calcium sulfate. Separating particulates and sulfur from flue gas requires the processing of large volumes of flue gas and leads to a significant thermal load on the plants. Treatment of waste in air, water, and solids is a concerning issue that has large impacts and costs that are hard to calculate. Improper solid and liquid waste management can lead to failures in the short term requiring remediation efforts, but the continued air pollution has become a top international concern for the long term. The future of allowable and untaxable air pollution is unclear. Thus, current combustion of raw coal leads to a plethora of issues concerning environmental safety, materials handling, and combustion efficiency.
Pre-combustion extractions of raw coal have been an intensive area of research for some time with a few promising methods for removing all of the sulfur and ash content reported recently, as summarized in Table 1 . The beneficiation methods are classified as biological, physical, or chemical. Beneficiation using microbes is slow, costly, and difficult to maintain or scale up. While physical remediation of coal is not suitable for chemically bonded minerals and requires energy intensive grinding, industrial implementations of physical coal cleaning methods can be found because of their ease of scalability.

Chemical beneficiation of raw coal is considered as the most promising method to effectively remove all sulfur forms. Acids and alkaline solutions can be used sequentially and in various mixtures to produce coal with both low ash and low sulfur. Some commercial ash-free coal methods requiring heated oil as solvent may exist, but the process is not economically feasible. Most of these extraction schemes are inspired from high-value materials; unfortunately, coal is a low-value commodity and these methods which call for even dilute acids and microwave radiation cannot be performed economically on an industrial scale. In addition, the residual acids and caustics in the coal, even in small amounts, will be combusted upon use, which creates new environmental challenges. Furthermore, the hydrocarbon bonds should not be broken down so as to retain heating value. While hydrothermal extractions have been used for clean coal, they usually decrease the heating value by a considerable amount due to organic dissolution and fractionation into gas and liquid phase (Timpe et al. 2001). Recently, a research group did show that carbonic acid could be used to enhance aqueous extraction of coal by bubbling $\mathrm{CO}_{2}$ through stagnant hot water, but the experimental temperatures and pressures were very mild (Gao et al. 2017; Ding et al. 2019).

Inspired by previous successful extraction efforts but keeping in mind the necessary thermo-economic

Table 1 Current sulfur removal technologies for coal beneficiation

\begin{tabular}{|c|c|c|c|c|c|}
\hline Previous studies & Extraction method & $\begin{array}{l}\text { Coal } \\
(\mathrm{g})\end{array}$ & $\begin{array}{l}\text { Water } \\
(\mathrm{g})\end{array}$ & $\begin{array}{l}\text { Temperature } \\
\left({ }^{\circ} \mathrm{C}\right)\end{array}$ & $\begin{array}{l}\text { Sulphur removal } \\
\text { (total \%) }\end{array}$ \\
\hline Uslu and Atalay (2004) & Magnetic physical & - & - & MW heating & $55 \%$ of pyritic \\
\hline $\begin{array}{l}\text { El-Midany and Abdel-Khalek } \\
\text { (2014) }\end{array}$ & Bascillus subtilis & 0.1 & 100 & 25 & $72 \%$ \\
\hline Mketo et al. (2016) & $3 \mathrm{M} \mathrm{HNO}_{3}-\mathrm{H}_{2} \mathrm{O}_{2}$ & 0.1 & 12 & $\begin{array}{l}180(\mathrm{MW} \\
\text { heating) }\end{array}$ & $102 \%$ \\
\hline Saikia et al. (2014) & $\mathrm{NaOH}-\mathrm{KOH}$ with sonication & 20 & 100 & 25 & $<50 \%$ \\
\hline Ambedkar et al. (2011) & $\begin{array}{l}2 \mathrm{~N} \mathrm{HNO}_{3}+3 \text { vol } \% \mathrm{H}_{2} \mathrm{O}_{2} \text { with } \\
\text { sonication }\end{array}$ & 20 & 500 & 25 & $41 \%$ \\
\hline Vasilakos and Corcoran (1983) & Chlorinated Water & 20 & 350 & $<100$ & $70 \%$ \\
\hline Baláž et al. (2001) & $5 \% \mathrm{NaOH}$ & 20 & 200 & 90 & $42 \%$ \\
\hline Timpe et al. (2001) & Hydrothermal & 40 & $10-300$ & 370 & $50 \%$ \\
\hline
\end{tabular}


restrictions for scale up on coal, we propose an extraction using supercritical mixtures of water and carbon dioxide. The mixture will form in situ carbonic acid capable of leaching heteroatoms from coal but also will be finely tunable to prevent loss of hydrocarbon heating value. Also, supercritical extractions have the benefit of simple separation upon completion of extraction using fractionation at decreasing pressures. Power plants would be able to use carbon dioxide generated from combustion, otherwise emitted, and use waste heat to perform economical and environmentally protective extractions on raw coal. Because sulfur comprises the majority of hazardous aerosolized pollutants by mass, sulfur is studied as a model heteroatom before and after extraction in this work.

\subsection{Supercritical fluid extraction}

Supercritical fluid extractions have several benefits including enhanced mass transport, ease of separation and recycle, wide range of extractive capability and tunability, and better inherent safety. A fluid is supercritical when it is compressed beyond its critical pressure and heated beyond its critical temperature, and the fluid density can be adjusted by changing pressure and temperature. The diffusivity of the supercritical fluids is higher than that of liquid solvents, and can be easily varied. For typical conditions, diffusivity in supercritical fluids is of the order of $10^{-3} \mathrm{~cm}^{2} / \mathrm{s}$ as compared to $10^{-1}$ for gases and $10^{-5}$ for liquids. The viscosity of typical supercritical fluids is of the order of $10^{-4} \mathrm{~g} /(\mathrm{cm} \mathrm{s})$ which is similar to that of gases and about 100 fold lower than that of liquids. The combination of the high diffusivity and low viscosity provide rapid equilibration of the fluid to the mixture to be extracted, hence extraction can be reached close to the thermodynamic limits. In addition, the supercritical temperature can be manipulated by changing the pressure, which can be done to ensure that the fluid mix is supercritical at the intended extraction temperature.

For many extraction applications in food and pharmaceutical industries, carbon dioxide is the supercritical fluid of choice because it is non-flammable, non-toxic, inexpensive, and has mild critical temperature $\left(31.1^{\circ} \mathrm{C}\right.$ and 74 bar). Hence, much of the attention has been given to supercritical carbon dioxide for practical extraction applications. However, $\mathrm{scCO}_{2}$ is too mild for extraction of hard minerals from materials such as coal.

One the other hand, water is supercritical at $>374{ }^{\circ} \mathrm{C}$ temperature and $>221$ bar pressure. Supercritical water has liquid-like density and gas-like transport properties, and behaves very differently than it does at room temperature. For example, it is highly non-polar, permitting complete solubilization of the most organic compounds and gases. The resulting single-phase mixture does not have many of the conventional transport limitations that are encountered in multi-phase reactors. The physiochemical properties of water, such as viscosity, ion product, density, and heat capacity, also change dramatically in the supercritical region with only a small change in the temperature or pressure, resulting in a substantial increase in the rates of chemical reactions (Gupta 2005). For example, Fig. 1 shows how density, dielectric constant and ionic product of water vary with temperature at 240 bar.

From Fig. 1, it is interesting to see that the dielectric behavior of $200{ }^{\circ} \mathrm{C}$ water is similar to that of ambient methanol, $300{ }^{\circ} \mathrm{C}$ water is similar to ambient acetone, $370{ }^{\circ} \mathrm{C}$ water is similar to methylene chloride, and $500{ }^{\circ} \mathrm{C}$ water is similar to ambient hexane (Gupta 2005). Hence, for our application of coal beneficiation, subcritical conditions (e.g., $300^{\circ} \mathrm{C}$ ) may provide a conducive solvent atmosphere where various ionic species are effectively solubilized in the fluid and removed.

\subsection{Combination of supercritical water and carbon dioxide (ScWC)}

The $\mathrm{CO}_{2}-\mathrm{H}_{2} \mathrm{O}$ ratio can be used to fine-tune the extraction efficiency. Ionization provided by the formed carbonic acid along with the high thermal energy can cause reaction of the inorganic content, and the products are then solubilized and efficiently carried away by the high density of the fluid. As shown in Fig. 2, the $\mathrm{CO}_{2}-\mathrm{H}_{2} \mathrm{O}$ ratio can also be used to tune the critical point of the mixture. With increasing pressure and carbon dioxide mass percent, the critical temperature of the mixture decreases from $623 \mathrm{~K}$ at $15 \%$ carbon dioxide concentration and low pressure to about $545 \mathrm{~K}$ at carbon dioxide concentration above $35 \%$ and pressure above $100 \mathrm{MPa}$. Dew point and bubble point lines indicate that carbon dioxide and water will be well miscible and soluble at temperatures above $530 \mathrm{~K}$.

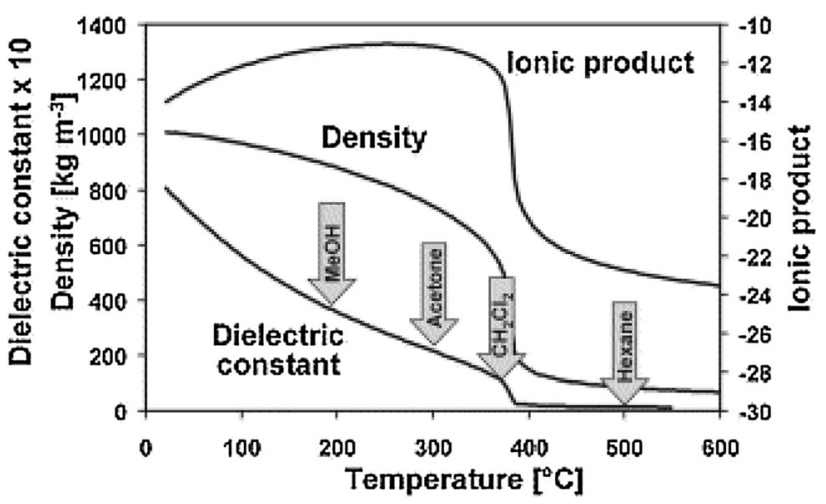

Fig. 1 Physical properties of water versus temperature, at 240 bar. Dielectric constants of typical organic solvents at room temperature are also indicated (Kritzer and Dinjus 2001) 


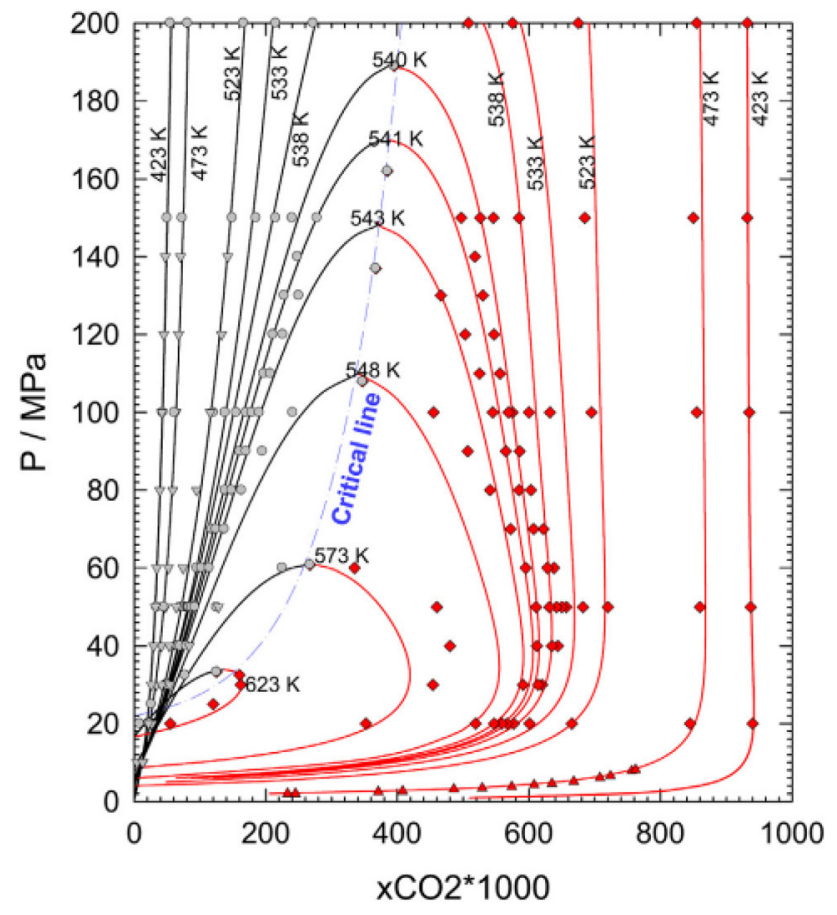

Fig. 2 Pressure-mole fraction phase diagram of the $\mathrm{CO}_{2}-\mathrm{H}_{2} \mathrm{O}$ system at temperatures of $423-623 \mathrm{~K}$ and pressures up to $200 \mathrm{MPa}$. The isotherms on the left of the critical line stand for the bubble point lines of $\mathrm{CO}_{2}$ saturated water, and the isotherms on the right of the critical line stand are dew point lines of the $\mathrm{H}_{2} \mathrm{O}$ saturated supercritical $\mathrm{CO}_{2}$. (Zhao and Lvov 2016)

\section{Experimental work}

\subsection{Materials}

Supercritical fluid grade $\mathrm{CO}_{2}$ and deionized water and their mixtures were used as extraction fluids. The pulverized bituminous coal with particle size 250-1250 micron was obtained from Rosebud Mining Company (Kittanning, PA) identified as Clymer Blend CPA\#101315. Nanopure filtered water was used for all testing. High purity SFE grade $\mathrm{CO}_{2}$ tank with dip tube was provided by Airgas. Coal standard 2683c was acquired from NIST. For analytical work, $70 \%$ environmental grade nitric acid from GFS Chemicals was used for ICP-OES. Boric acid was purchased from the American Borate Company, and pure sodium sulfate and sodium hydroxide were purchased from Sigma Aldrich.

\subsection{Analytical techniques}

For elemental analysis of solids, Inductively Coupled Plasma Mass Spectroscopy of coal pellets was performed on an Agilent ICP-MS. A $1550 \mathrm{~W}$ laser $\left(8 \mathrm{~J} / \mathrm{cm}^{2}\right)$ would be focused on the pellet and used to ablate and ionize the pellet surface at low pressure in the presence of plasma gas.
Ions are swept by nebulizer gas into the spectroscopy unit and produce counts for each element. A laser spot size of 75 microns was used to ablate $5 \mathrm{~mm}$ of pellet to $7.0 \mathrm{~mm}$ depth while rastering at 75 micron/s. Line length could be adjusted to obtain an appropriate number of counts to build calibration curves. The experimental error in the sulfur analysis is expected to be $5 \%$.

For validation and additional testing, samples were also sent to Standard Laboratories, Inc. (South Charleston, WV) for analysis specialized to coal samples.

A Hitachi SU-70 FE-SEM was used to obtain images and EDS spectra. Raman shift and XRD and BET were used as well to understand physical and chemical changes to the carbon structure.

\subsection{Coal extraction apparatus}

A semi-continuous coal extractor was designed and built as shown in Fig. 3, in which coal powder is packed in the extraction vessel and the extraction fluid is pumped continuously.

A high-pressure hydrothermal reactor (model XHTC400 USP-1200) from Columbia International was used as a flow vessel to extract coal solids. The vessel volume is $250 \mathrm{~mL}$ and material of construction is S316 stainless steel. The vessel itself is rated to a maximum continuous working temperature of $400{ }^{\circ} \mathrm{C}$, maximum temperature of $450{ }^{\circ} \mathrm{C}$, and a maximum working pressure of 200 bar. A Supercritical 24 constant flow/constant pressure dual-piston pump was used to pressurize the vessel with $\mathrm{CO}_{2}$. An Eldex 1SMP pump $(0-5 \mathrm{~mL} / \mathrm{min},<200 \mathrm{bar})$ was used to pump water. The two streams meet at a tee joint that immediately feeds to a check valve at the vessel inlet. The vessel was heated with a Rama $1000 \mathrm{~W}$ heating band controlled by a temperature controller. A Swagelok KPB1P0A422P20000 backpressure regulator was used to control the pressure of the outlet. Gas exiting from the regulator was fed to room temperature separator to allow aqueous suspension leachate to separate from gaseous $\mathrm{CO}_{2}$.

In a typical extraction, the cooling/chilling unit on the Supercritical 24 pump were turned on and allowed to cool for $20 \mathrm{~min}$. The vessel was loaded with about $10-50 \mathrm{~g}$ of pulverized coal and covered with porous glass wool to suppress carryover of the coal particles by the extraction fluid. The vessel was tightened and the backpressure regulator left slightly open. If the extraction called for water, the Eldex pump would be then be primed, turned off, and connected to the vessel inlet. The $\mathrm{CO}_{2}$ tank was then opened and the pump turned on. The regulator was then closed all the way and checked for zero outlet flow. The vessel was allowed to fully pressurize to 153 bar with only $\mathrm{CO}_{2}$ over the course of about $25 \mathrm{~min}$ at which point the backpressure regulator was opened and a steady flow 


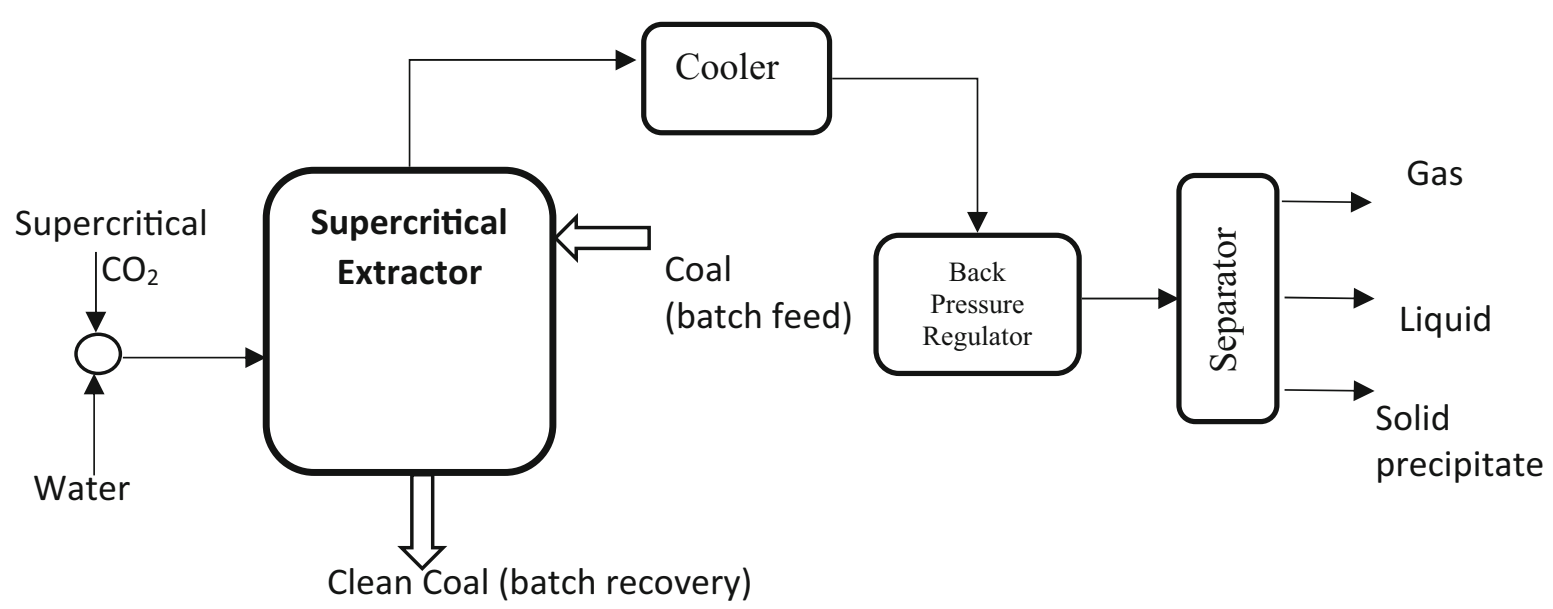

Fig. 3 Schematic of the semi-continuous supercritical $\mathrm{H}_{2} \mathrm{O}-\mathrm{CO}_{2}(\mathrm{ScWC})$ extraction of coal

established. The temperature controller was then turned on and set to $75^{\circ} \mathrm{C}$. If the extraction called for water, the Eldex pump would also be turned on. Once the vessel reached about $50{ }^{\circ} \mathrm{C}$, the setpoint was increased to $175^{\circ} \mathrm{C}$ and then again to desired set point. Heating to desired set temperature would take about $25 \mathrm{~min}$. Extraction time is then considered to be time zero once the vessel has reached the desired temperature. Upon completion of an extraction, both pumps and the heating would be turned off and the $\mathrm{CO}_{2}$ tank closed. The regulator was loosened to completely depressurize the vessel and then closed to allow the evacuated vessel to cool overnight. Usually, the vessel temperature would increase past reaction temperature at the beginning of cooling as incoming fluid was shut off and no longer provided a heat duty. Coal solids were weighed before and after extraction. Other than solids embedded in the glass wool used a filter, total coal mass did not seem to change during extraction. Liquid and solid samples would be collected the next day and stored for analysis.

Typical temperature and pressure profiles of the reactor versus time are shown in the Fig. 4.

Extracted and raw coals were dried at $80{ }^{\circ} \mathrm{C}$ in a vacuum oven for $12 \mathrm{~h}$. The entire portion would then be ground with a mortar and pestle and mixed together. A roughly $100 \mathrm{mg}$ portion of that coal mixture would then be dried in a vacuum oven at $80{ }^{\circ} \mathrm{C}$ and $-100 \mathrm{psi} / \mathrm{g}$ for two hours to ensure moisture removal. Approximately $32 \mathrm{mg}$ coal and $593 \mathrm{mg}$ boric acid were then weighed, mixed, and ground together with a high-energy ball mill. An $11 \mathrm{~mm}$ die was used to press pellets at 3 tons of applied force for 2 min. Pellets were fashioned with various amounts of a NIST coal standard (sulfur, $2 \mathrm{wt} \%$ ) in order to create a calibration curve. The pellets were then taken for sulfur analysis using ICP-MS with laser ablation.

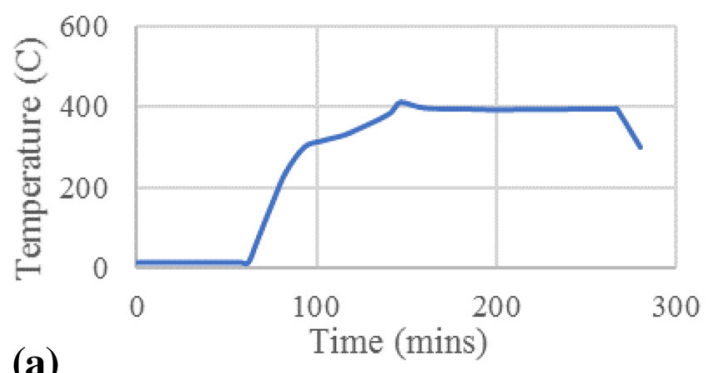

(a)

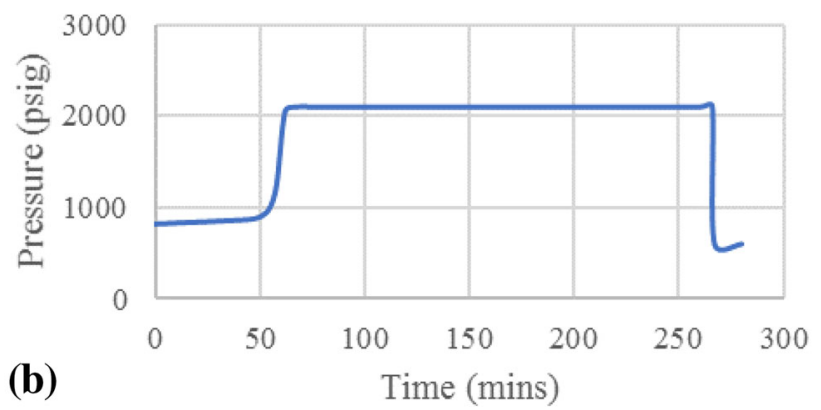

Fig. 4 Temperature (a) and pressure (b) profiles for a typical experiment. Data for experiment E102219 for which the extraction is considered to start at $143 \mathrm{~min}$ timescale

\section{Results and discussion}

\subsection{Results}

The coal feedstock was analyzed independently by Standard Laboratories using prescribed ASTM methods. The analysis is shown in the Table 2. It showed a $1.14 \mathrm{wt} \%$ sulfur content using ASTM D2492. Our in-house ICP-MS analysis gave a similar sulfur content of $1.15 \mathrm{wt} \%$, but due to high variation, the coal was mixed more thoroughly and a raw value of $1.37 \mathrm{wt} \%$ was obtained thereafter. 
Table 2 Analysis of the feedstock coal

\begin{tabular}{lll}
\hline Item & Dry & ASTM method \\
\hline Ultimate analysis & & \\
$\%$ Nitrogen & 1.56 & D5373 \\
$\%$ Carbon & 81.96 & D5373 \\
$\%$ Hydrogen & 4.76 & D5373 \\
\% Oxygen & 4.38 & D3176 \\
Total & 92.65 & \\
\% Moisture & & D3302 \\
Proximate analysis & & \\
Heating value (btu/lb) & 14,685 & D5865 \\
$\%$ Ash & 6.20 & D3174 \\
\% Sulfur & 1.14 & D4239 \\
$\%$ Volatile & 25.36 & D3175 \\
$\%$ Fixed carbon & 68.44 & D3172 \\
lbs SO2/MM BTU & & \\
lbs ASH/MM BTU & & \\
Sulfur forms & & D6721 \\
\% Sulfate & 0.02 & D2492 \\
\% Pyritic & 0.50 & D2492 \\
\% Organic & 0.62 & \\
Total & 1.14 & \\
Chlorine (ppm) & 1,895 & \\
Mercury (ppm) & 0.116 & \\
\hline Bold & & \\
\hline
\end{tabular}

Bold represents the subgroup
A total of 17 extraction runs were carried out using the above bituminous coal at a constant pressure of $143 \mathrm{bar}$ with varying extraction time, temperature, water flow rate and $\mathrm{CO}_{2}$ flow rate, as shown in Table 3. The sulfur content was tracked by ICP-MS analysis in the extracted coal as a measure of extraction effectiveness. Standard Labs results are also presented when available.

Experiments were performed at various temperatures with $\mathrm{CO}_{2}$ flow, $\mathrm{H}_{2} \mathrm{O}$ flow (hydrothermal), and combined flow (ScWC) in order to asses the effectiveness of supercritical carbon dioxide as solvent and to compare combined flow extraction to more typical hydrothermal extractions. Because fluid characteristics can vary complexly with $\mathrm{CO}_{2}-\mathrm{H}_{2} \mathrm{O}$ ratio, a variety of temperatures were explored ranging from 200 to $400{ }^{\circ} \mathrm{C}$, and sulfur remaining was used as a measure of effectiveness. The coal mass was varied slightly as we came to understand the amount needed for analysis but changes are negligible. The fluid path of our vessel does not directly cross through the loaded solids, so it is likely that the solvent to coal ratios are all higher than necessary. Further testing will be need to understand the mass transfer characteristics in a well design flow path. For the same reason, in the present study, the differences in time are not as important as changes in temperature and fluid composition.

Solids recovered after extraction were usually within $2 \%$ of the mass loaded after accounting for loss of moisture, except for extractions with pure water at temperatures

Table 3 Master list of coal extraction experiments conducted

\begin{tabular}{|c|c|c|c|c|c|c|}
\hline Experiment & Temperature $\left({ }^{\circ} \mathrm{C}\right)$ & Time $(\min )$ & Coal $(\mathrm{g})$ & $\mathrm{H}_{2} \mathrm{O}(\mathrm{g} / \mathrm{min})$ & $\mathrm{CO}_{2}(\mathrm{~g} / \mathrm{min})$ & Sulfur (ICP-MS, wt \%) \\
\hline E120218 & 200 & 30 & 48 & & 5.82 & $1.13(\mathrm{SL}=1.16)$ \\
\hline E020519 & 275 & 45 & 49 & & 7.76 & 1.15 \\
\hline E020619 & 275 & 60 & 50 & 0.50 & 5.82 & 1.03 \\
\hline E022619 & 275 & 180 & 49 & & 7.76 & 1.06 \\
\hline E032019 & 275 & 180 & 49 & 0.50 & 5.82 & 0.98 \\
\hline E032119 & 275 & 180 & 47 & 4.99 & & 1.07 \\
\hline E042519 & 350 & 60 & 16 & & 5.82 & 0.92 \\
\hline E061919 & 350 & 60 & 30 & 0.50 & & 0.90 \\
\hline E061819 & 350 & 60 & 23 & & 11.64 & 0.73 \\
\hline E062519 & 350 & 60 & 20 & 4.99 & 0.48 & 0.83 \\
\hline E071019 & 320 & 60 & 18 & 2.49 & 11.64 & 0.74 \\
\hline E072419 & 290 & 60 & 19 & 2.49 & & 0.71 \\
\hline E072619 & 290 & 60 & 18 & & 11.64 & 1.01 \\
\hline E081719 & 350 & 90 & 11 & 3.74 & 17.46 & 0.82 \\
\hline E092619 & 395 & 135 & 10 & & 11.64 & 0.92 \\
\hline E102219 & 395 & 120 & 10 & 2.49 & 7.76 & $0.87(\mathrm{SL}=0.83)$ \\
\hline E121619 & 395 & 120 & 25 & 2.49 & 7.76 & 1.05 \\
\hline
\end{tabular}




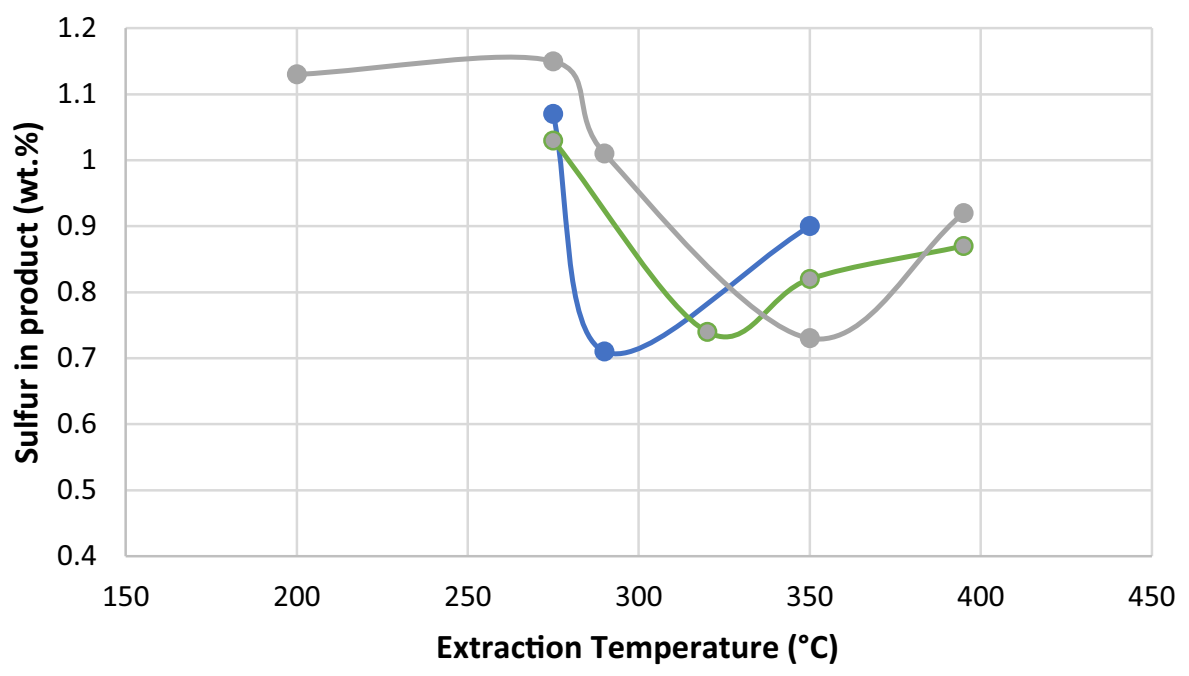

$\longrightarrow$ Hydrothermal $\longrightarrow$ ScWC $\longrightarrow \mathrm{CO} 2$

Fig. 5 Sulfur remaining in coal after extraction using hydrothermal, $\mathrm{ScWC}$, and $\mathrm{CO}_{2}$

around $350{ }^{\circ} \mathrm{C}$ where about $10 \%$ of the mass was lost. The exact masses recovered were difficult to obtain as some coal particles entangle in the glass wool used as filter.

Data in Fig. 5 shows that carbon dioxide, ScWC, and hydrothermal extraction are all similarly capable of extracting $50 \%$ sulfur. Extraction with carbon dioxide was most effective at $350{ }^{\circ} \mathrm{C}$, while extraction with water seemed to be most effective around $300{ }^{\circ} \mathrm{C}$ where the ionic concentration was highest. As expected, the hydrothermal extraction was more aggressive at lower temperatures than the carbon dioxide, and the mixture was somewhere in between. Combined flow may provide a synergy that increases extraction but more accurate assessment of the raw coal would be necessary. ScWC, or combined flow, does seem to inhibit organic dissolution that would be expected and was seen from strictly hydrothermal extraction. Although a limited testing was done with flowrate, increasing the flowrate of carbon dioxide extraction at $350{ }^{\circ} \mathrm{C}$ from 5.82 to $11.64 \mathrm{~g} / \mathrm{min}$ did result in reducing sulfur content from $0.92 \mathrm{wt} \%$ to $0.73 \mathrm{wt} \%$.

While we studied only a single-step desulfurization reactions, analysis of the sulfur forms indicated that extraction with pure carbon dioxide at $200{ }^{\circ} \mathrm{C}$ caused pyritic sulfur to be transformed into sulfates that may be easily washed out with warm water. While raw coal contained only $0.02 \%$ sulfate and $0.50 \%$ pyritic sulfur, E120218 contained $0.16 \%$ sulfate and $0.28 \%$ pyritic sulfur.

In the case of the combined and hydrothermal extractions at $395{ }^{\circ} \mathrm{C}$, the powder coal feedstock turned into a porous-fused mass by a process called hydrothermal carbonization (Fig. 6). Opaque yellow product was typical for all successful extractions. BET analysis showed that solid product surface area was low, with surface area of $14 \mathrm{~m}^{2} / \mathrm{g}$ and average pore radius of $9.9 \AA$, probably similar to raw coal, which could not be analyzed due to volatile sulfur content. The coal after the extraction at lower temperatures was not fused.

Extracted coal from E102219 was further sent out for proximate analysis to the Standard Laboratories. The results are compared with the coal feedstock in Table 4. The volatile carbon portion of the raw coal, $25 \%$, had decreased to $12.5 \%$ with a corresponding increase in fixed carbon for E102219. Samples E102219 and E062519 both had substantially less carbon ablated during ICP-MS than all other samples. ICP-MS sulfur weight percentages are in accordance with Standard Labs traditional pyrolysis results for selected samples.

To further understand the characteristics of the extracted coal from E102219 experiment, X-ray diffraction and thermo-gravimetric analyses were carried out and the results are compared to raw coal in Fig. 7.

XRD spectra for coal contain two main peaks for carbon at $2 \theta$ of $25^{\circ}$ and $26.5^{\circ}$. Raw coal has a more prominent peak at $25^{\circ}$ with a smaller peak at $26.5^{\circ}$. For E102219, the higher intensity indicates a more ordered crystalline structure as compared to raw coal. Also, the peak at $26.5^{\circ}$ has become larger than the peak at $25^{\circ}$. The $26.5^{\circ}$ peak is associated with synthetic graphite, and the peak at $25^{\circ}$ can be attributed to carbon that is not graphitic.

Thermogravimetric analysis was carried out in nitrogen atmosphere and shows the difference in volatility between raw and extracted coal. By $800{ }^{\circ} \mathrm{C}$, the raw sample has lost $23.2 \%$ of mass, compared to only $7.7 \%$ mass for E1022. Although we extracted only to $395{ }^{\circ} \mathrm{C}, \mathrm{E} 102219$ is considerably less volatile in the range of $400-800{ }^{\circ} \mathrm{C}$. 


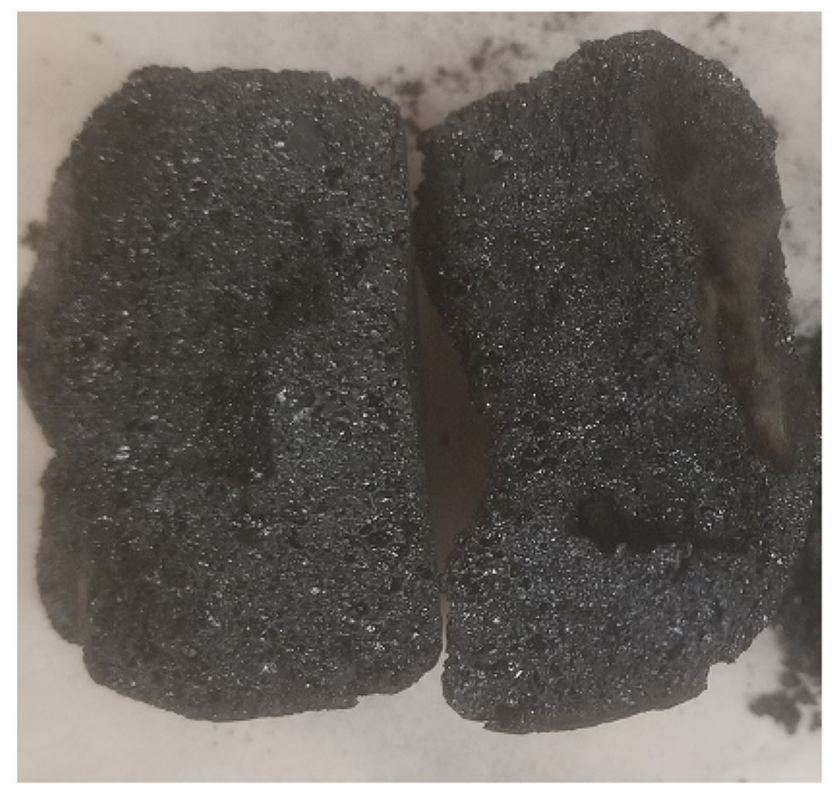

(a) Coal

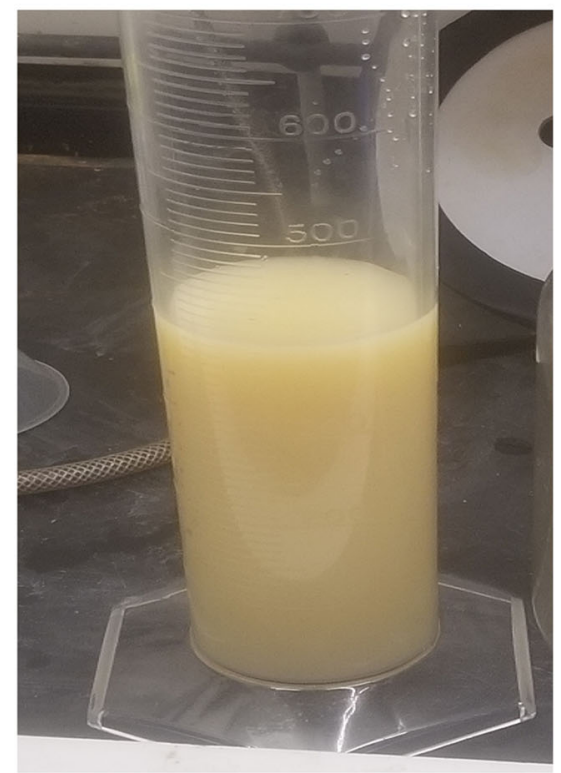

(b) Dissolved minerals

Fig. 6 Products from experiment E102219: a coal and b dissolved minerals

Raman spectra for raw sample have higher counts and a more angled baseline due to fluorescence of metals contained in the raw coal (Fig. 8). This fluorescence is not noticed in the extracted sample from E102219, which has a nearly flat baseline and lower noise, indicating a lack of fluorescence generating metals. Two characteristic carbon peaks appear at 1350 and $1600 \mathrm{~cm}^{-1}$. With baseline subtracted, the peak heights and ratios are the same. A slight
Table 4 Proximate analysis of the extracted coal from experiment E102219

\begin{tabular}{lll}
\hline Proximate analysis & Raw coal & Extracted coal from E102219 \\
\hline Heating value (btu/lb) & 14,685 & 14,113 \\
\% Ash & 6.20 & 6.87 \\
\% Sulfur & 1.14 & 0.83 \\
\% Volatile & 25.36 & 12.47 \\
\% Fixed carbon & 68.44 & 80.66 \\
\hline
\end{tabular}

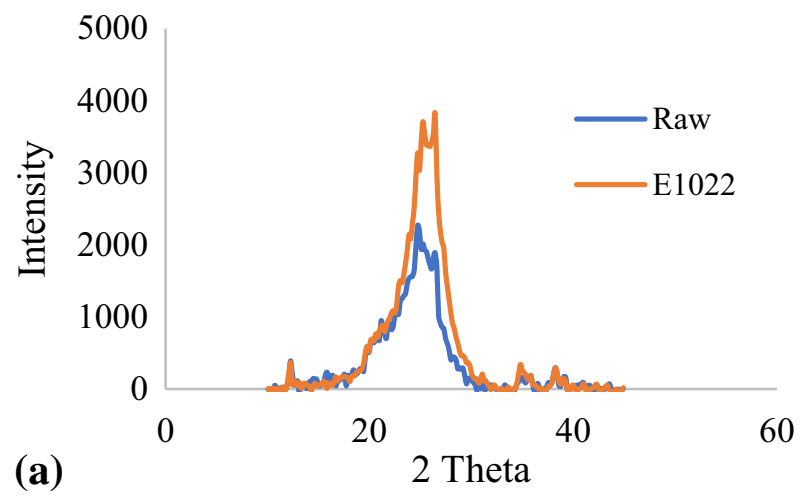

(b)

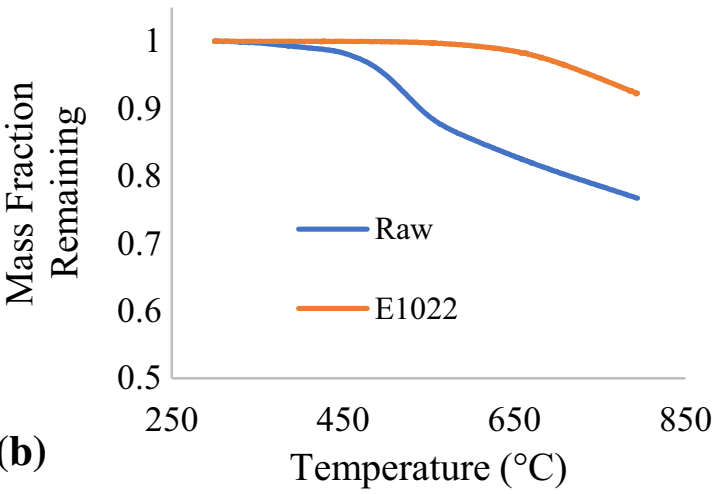

Fig. 7 X-ray diffraction analysis a and thermo-gravimetric analysis b of the extracted (E102219) and raw coals

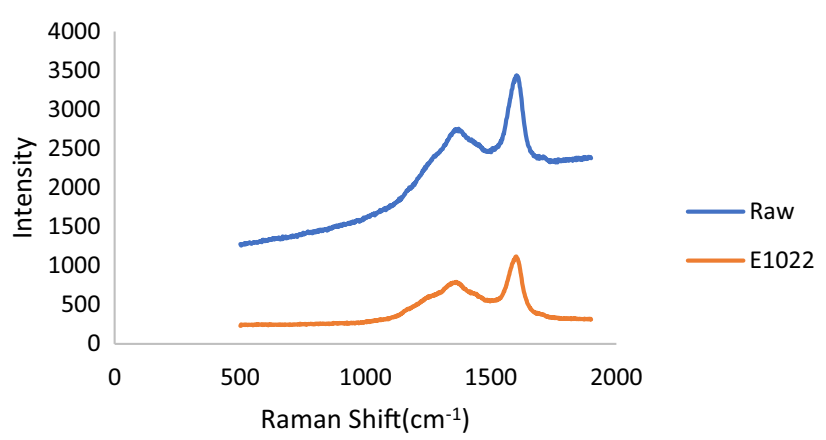

Fig. 8 Raman shift spectra for raw coal and the extracted coal from E102219 
broadening of the peak at $1350 \mathrm{~cm}^{-1}$ is noticeable with two shoulder peaks becoming more prominent.

Thus, the extraction with fluid above the supercritical point of pure water $\left(375^{\circ} \mathrm{C}\right)$ caused hydrothermal carbonization which may be useful for further upgrading carbon once the heteroatoms have been extracted at temperatures between 300 and $350{ }^{\circ} \mathrm{C}$. The presence of carbon dioxide during hydrothermal carbonization may cause volatile carbon content to crosslink in the solid instead of being extracted by the solution. From the proximate analysis, E102219 has retained most of its heating value. Removing the sulfur should decrease the heating value slightly, but crosslinking volatile carbon into fixed carbon would increase the heating value. Importantly, the combined extraction seems to crosslink carbons that would be extracted and lost by hydrothermal extraction. A survey of the extractive reactions involved is presented below.

\subsection{Extractive reactions involved}

Water molecule dissociates to form hydrogen ion and hydroxyl ion that both participate in further extraction reactions. At room temperature, the ions are in small concentration, and the dissociation increased with temperature up to about $300{ }^{\circ} \mathrm{C}$ and then it rapidly drops, as shown in Fig. 1 (Kritzer and Dinjus 2001). Thermal energy promotes the diffusion and reaction of the ions with the elements in the coal matrix.

$\mathrm{H}_{2} \mathrm{O} \rightarrow \mathrm{H}^{+}+\mathrm{OH}^{-}$

Carbon dioxide dissolve in water to form carbonic acid following the reaction below:

$\mathrm{CO}_{2}+\mathrm{H}_{2} \mathrm{O} \rightarrow \mathrm{H}_{2} \mathrm{CO}_{3}$

$\mathrm{H}_{2} \mathrm{CO}_{3} \rightarrow \mathrm{HCO}_{3}^{-}+\mathrm{H}^{+}$

$\mathrm{HCO}_{3}^{-}+\mathrm{OH}^{-} \rightarrow \mathrm{CO}_{3}^{2-}+\mathrm{H}_{2} \mathrm{O}$

Carbonic acid can then reacts to dissolve metals into solution or to form carbonate salts. $(\mathrm{M}=\mathrm{Ca}, \mathrm{Mg}$, etc. $)$

$\mathrm{CO}_{3}^{2-}+\mathrm{M}_{(\text {mineral })}^{2+} \rightarrow \mathrm{MCO}_{3(\mathrm{~s})}$

$\mathrm{MCO}_{3(\mathrm{~s})}+\mathrm{H}_{2} \mathrm{CO}_{3} \rightleftharpoons \mathrm{M}_{(\mathrm{aq})}^{2+}+2 \mathrm{HCO}_{3}^{-}$

$\mathrm{MCO}_{3(\mathrm{~s})}+$ heat $\rightarrow \mathrm{MO}+\mathrm{CO}_{2}$

The $\mathrm{CO}_{2}-\mathrm{H}_{2} \mathrm{O}$ mixture is acidic which will help to break down complex mineral structure and provide access to metal ions. Many complex reactions have been hypothesized regarding the specific forms of sulfur. Although this paper does not attempt to study these reactions, a comprehensive analysis of the reaction network can further help understand the molecular mechanism involved so that a rational design for industrial level extraction plants can be made.

For pyrite, iron and sulfur can react with various forms of hydrogen, carbonate, and oxygen ions to ultimately form iron, iron sulfates, sulfur dioxide, and hydrogen sulfide. Pyrite can also be converted into sulfate. Reactive sulfur species COS may also be formed, via a network of reactions as

$$
\begin{aligned}
& \mathrm{FeS}+\mathrm{H}_{2} \mathrm{CO}_{3} \rightarrow \mathrm{FeCO}_{3}+\mathrm{H}_{2} \mathrm{~S} \\
& \mathrm{SO}_{2}+\mathrm{H}_{2} \mathrm{O} \rightleftharpoons \mathrm{H}_{2} \mathrm{SO}_{3} \\
& \mathrm{SO}_{2}+2 \mathrm{H}_{2} \mathrm{O} \rightleftharpoons \mathrm{H}_{2}+\mathrm{H}_{2} \mathrm{SO}_{4} \\
& 4 \mathrm{SO}_{2}+4 \mathrm{H}_{2} \mathrm{O} \rightleftharpoons 3 \mathrm{H}_{2} \mathrm{SO}_{4}+\mathrm{H}_{2} \mathrm{~S} \\
& \mathrm{H}_{2} \mathrm{~S}+\mathrm{CO} \rightarrow \mathrm{COS}+\mathrm{H}_{2} \\
& \mathrm{H}_{2} \mathrm{~S}+\mathrm{CO}_{2} \rightarrow \mathrm{COS}+\mathrm{H}_{2} \mathrm{O}
\end{aligned}
$$

Organic sulfur is found in coal as mercaptans (RSH), disulfides (RS-S-R'), sulfides (R-S-R'), and thiophenes (heterocyclic). Organic sulfur is thus integrated into the carbon structure and difficult to remove. Oxidative ions convert organic sulfur to sulfates which can be dissolved in water or form sulfur dioxide.

$$
\begin{aligned}
& \mathrm{RSH}+\mathrm{H}_{2} \mathrm{O} \rightarrow \mathrm{ROH}+\mathrm{H}_{2} \mathrm{~S} \\
& \mathrm{RSH}+\mathrm{CO}_{2} \rightarrow \mathrm{ROH}+\mathrm{COS}
\end{aligned}
$$

Interaction of fluid with the coal may also cause lower organics to liquify or gasify to produce carbon dioxide, hydrogen gas, or methane. More complex studies of the reactions involved can be found in other recent studies (Morimoto et al. 2008; Tian et al. 2016; Zhang et al. 2018).

\subsection{Industrial application}

The proposed supercritical water-carbon dioxide (ScWC) extraction technology has potential to help industry in mitigating hazardous aerosol pollutant emission, reducing the need to treat flue gas, and increasing the use of flue gas streams. Successfully removing sulfur and other hazardous molecules from the raw coal before combustion would eliminate pollution of ash, limestone slurry, and air. While many post combustion efforts prove to trade one form of pollution for another, our proposed pre-combustion extraction process seeks to reduce waste in all three phases. In the traditional combustion, treating the flue gas instead of raw coal results in a substantial volume of gas to be processed. This also hinders the ability to further harvest thermal energy from the stream; small improvements in the thermal efficiency of large power plants can have drastic overall economic effects. Pollutant-free flue gas stream may also allow for direct compression of carbon dioxide for sequestration and use. The proposed process has 
potential to provide new synergy with oxyfuel combustion, Brayton cycle, and enhanced oil recovery technologies. The presence of sulfur and mercury is the main reason for coal processing for power generation to become an expensive proposition. Removing them pre-combustion also offers the potential to use coal for other beneficiated products where these two elements are not desired in the products. Again, the use of $\mathrm{CO}_{2}$ and $\mathrm{H}_{2} \mathrm{O}$ mixture has potential for industrial applications in the power plants as both $\mathrm{CO}_{2}$ and $\mathrm{H}_{2} \mathrm{O}$ are available on site.

\section{Conclusion}

Supercritical water- $\mathrm{CO}_{2}(\mathrm{ScWC})$ and supercritical $\mathrm{CO}_{2}$ extractions are proposed for cleaning of coal before combustion. The coal beneficiation is demonstrated in 200-400 ${ }^{\circ} \mathrm{C}$ range at 143 bar using a semi-continuous process without needing any mineral acid or organic solvents by studying the sulfur removal. Carbon dioxide extraction at $350{ }^{\circ} \mathrm{C}$ is effective similar to the typical hydrothermal extraction which was most effective at $290{ }^{\circ} \mathrm{C}$. Extraction with carbon dioxide caused more difficult-to-remove pyritic and organic sulfurs to become sulfate by $200{ }^{\circ} \mathrm{C}$. Extracted solids contained about $50 \%$ less sulfur than raw coal for 1-h extractions using $\mathrm{CO}_{2}$ at $350{ }^{\circ} \mathrm{C}$, water at $290{ }^{\circ} \mathrm{C}$ or combined $\mathrm{H}_{2} \mathrm{O}-\mathrm{CO}_{2}$ at $320{ }^{\circ} \mathrm{C}$. While hydrothermal extraction slightly decreased the mass of coal recovered (about 10\%), ScWC extraction cause any loss of carbon content. Thus, the extractive strength of the fluid can be tuned by adjusting the temperature and $\mathrm{H}_{2} \mathrm{O}$ / $\mathrm{CO}_{2}$ flow ratio. Extraction with pure water above the supercritical point of pure water caused hydrothermal carbonization of coal solids where volatile carbons were crosslinked into fixed carbons. Carbonization caused the coal mass to fuse upon drying and may be interesting for further carbon upgrading, but should be avoided for coal meant to be combusted. Hence, it is preferable to operate at $320{ }^{\circ} \mathrm{C}$ or below to obtain a free-flowing extracted coal.

Acknowledgement This study was supported by the Office of Fossil Energy, U.S. Department of Energy via Leonardo Technologies, Inc., subcontract LTI-F80022594-VCU. Authors are thankful to Rosebud Mining Company for providing coal sample and to Prof. Arif Sikdar (VCU Center of Environmental Studies) for scientific discussions.

Open Access This article is licensed under a Creative Commons Attribution 4.0 International License, which permits use, sharing, adaptation, distribution and reproduction in any medium or format, as long as you give appropriate credit to the original author(s) and the source, provide a link to the Creative Commons licence, and indicate if changes were made. The images or other third party material in this article are included in the article's Creative Commons licence, unless indicated otherwise in a credit line to the material. If material is not included in the article's Creative Commons licence and your intended use is not permitted by statutory regulation or exceeds the permitted use, you will need to obtain permission directly from the copyright holder. To view a copy of this licence, visit http://creativecommons. org/licenses/by/4.0/.

\section{References}

Ambedkar B, Nagarajan R, Jayanti S (2011) Ultrasonic coal-wash for de-sulfurization. Ultrasonic Sonochem 18:718-726

Baláž P, LaCount RB, Kern DG (2001) Chemical treatment of coal by grinding and aqueous caustic leaching. Fuel 80:665-671

Ding L, Gao Y, Li X, Wang Wenhui, Xue Yi, Zhu Xianqing, Xu Kai, Hu Hongyun, Luo Guangqian, Naruse Ichiro, Yao Hong (2019) A novel $\mathrm{CO}_{2}$-water leaching method for AAEM removal from Zhundong coal. Fuel 237:786-792

El-Midany AA, Abdel-Khalek MA (2014) Reducing sulfur and ash from coal using Bacillus subtilis and Paenibacillus polymyxa. Fuel 115:589-595

Energy Information Agency (2018) International energy outlook 2017 https://www.eia.gov/todayinenergy/detail.php?id=37293. Accessed 21 March 2020

Gao YX, Ding LZ, Li X, Wang Wenhui, Xue Yi, Zhu Xianqing, Hu Hongyun, Luo Guangqian, Naruse Ichiro, Bai Zongqing, Yao Hong (2017) Na\&Ca removal from Zhundong coal by a novel $\mathrm{CO}_{2}$-water leaching method and the ashing behavior of the leached coal. Fuel 210:8-14

Gupta RB (2005) Supercritical water oxidation. In: Encyclopedia of chemical processing, Marcel Dekker, New York

Kritzer P, Dinjus E (2001) An assessment of supercritical water oxidation (SWO). Existing problems, possible solutions and new reactor concepts. Chem Eng J 83(3):207-214

Mketo N, Nomngongo PN, Ngila JC (2016) Evaluation of different microwave-assisted dilute acid extracting reagents on simultaneous coal desulphurization and demineralization. Fuel 163:189-195

Morimoto M, Nakagawa H, Miura K (2008) Hydrothermal extraction and hydrothermal gasification process for brown coal conversion. Fuel 87:546-551

Saikia BK, Dutta AM, Saikia L, Shahid Ahmed, Bimala P.Baruah (2014) Ultrasonic assisted cleaning of high sulphur Indian coals in water and mixed alkali. Fuel Process Technol 123:107-113

Tian LN, Yang W, Chen ZH, Wang Xianhua, Yang Haiping, Chen Hanping (2016) Sulfur behavior during coal combustion in oxy-fuel circulating fluidized bed condition by using TGFTIR. J Energy Inst 89(2):264-270

Timpe RC, Mann MD, Pavlish JH, Klouie PK (2001) Organic sulfur and hap removal from coal using hydrothermal treatment. Fuel Process Technol 73:127-141

Uslu T, Atalay Ü (2004) Microwave heating of coal for enhanced magnetic removal of pyrite. Fuel Process Technol 85:21-29

Vasilakos NP, Corcoran WH (1983) Solvent effects in coal desulphurization by chlorinolysis near ambient temperature. Fuel 62:1111-1115

Zhang LJ, Li ZH, He WJ, Li Jinhu, Qi Xuyao, Zhu Jing, Zhao Lanming, Zhang Xue (2018) Study on the change of organic sulfur forms in coal during low-temperature oxidation process. Fuel 222:350-361

Zhao H, Lvov SN (2016) Phase behavior of the $\mathrm{CO}_{2}-\mathrm{H}_{2} \mathrm{O}$ system at temperatures of 273-623 K and pressures of 0.1-200 MPa using Peng-Robinson-Stryjek-Vera equation of state with a modified Wong-Sandler mixing rule: an extension to the $\mathrm{CO}_{2}-\mathrm{CH}_{4}-\mathrm{H}_{2} \mathrm{O}$ system. Fluid Phase Equilib 417:96-108 